\section{ELECTRICAL WORK}

In the following circuits the latest BS symbols must be used. Draw the following circuits:

1 Two lighting points controlled from two points using two single-pole two-way switches and using the normal method of two-way control.

2 Draw a signalling circuit using the following components; two push button switches, two electric bells, an ammeter, a voltmeter and a $12 \mathrm{~V}$ battery.

3 Using two filament lights, a fuse, a singlepole one-way switch, two single-pole twoway switches, draw a suitable circuit for a hall light having its own switch and a landing light controlled by either of the other two switches. Show both lights off.

4 Using a step-down transformer to supply the current draw a bell signalling circuit.

5 Two lighting points controlled from four points by two single-pole two-way switches and two single-pole intermediate switches.

6 Make freehand sketches of the following:

(a) a single-pole knife switch;

(b) a simple electrical cell;

(c) the element of an electric iron;

(d) a 3 pin 15 A plug with cover removed to show the internal construction;

(e) a batten type lampholder assembled and then show an exploded view; (f) sketches to show how a married joint is completed;

(g) a 1.3 A fused plug which has rectangular pins, with cover removed and showing the fuse in position. Mark the $\mathrm{L}, \mathrm{N}$ and $\mathrm{E}$ terminals respectively.

7 Draw a circuit diagram to show how a car battery is charged using a transformer with a half-wave rectifier.

8 A fuseboard which has four lugs for $\phi \cdot M 10$ bolts spaced $380 \mathrm{~mm}$ between centres horizontally and $304 \mathrm{~mm}$ between centres vertically is to be mounted to a vertical steel stanchion. The stanchion which measures $202 \times 64 \mathrm{~mm}$ I section must not be drilled or welded. Produce fully dimensioned sketches of the brackets and fixings that you would use for mounting the fuseboard on the stanchion.

9 Sketch freehand the main constructional details of a single-element electric fire which has a parabolic reflector.

10 Sketch the latest BS symbols used to represent:

(a) electric buzzer;

(b) transformer;

(c) single-pole tumbler switch;

(d) a capacitor.

11 Produce a neat sketch showing the interior of a trembler bell. The connections to the push and battery must be shown. You may use drawing instruments.

12 Draw a circuit diagram showing a resistance, and inductor and a capacitor connected in parallel to an AC supply. 